\title{
La comunicación como acto esencial en la mejora de la evaluación mediante pruebas estandarizadas
}

\author{
Sandra Araya-Leal
}

En los últimos tiempos, nuevas tendencias evaluativas agrupadas bajo el concepto de 'evaluación auténtica' han propuesto ideas diferentes a los tests estandarizados con la lógica de individualizar la evaluación, haciéndola más profunda, exhaustiva y significativa. Aun así, los precursores de esta línea reconocen la mayor complejidad y coste de la implementación de estos procesos y el grado de subjetividad en torno a ellos [1].

En el área de la educación médica, aun cuando muchas instituciones han incorporado nuevos elementos que permiten diversificar la evaluación (estudios de casos, portafolios, trabajos grupales, etc.), los tests escritos estandarizados siguen siendo una herramienta fundamental para corroborar aprendizajes al finalizar un ciclo $[2,3]$.

Cuando el estudiante se enfrenta a una evaluación estandarizada, sea presencial o a distancia, de preguntas abiertas o cerradas, se encuentra ante un examen homogéneo que, sin embargo, será respondido por un grupo heterogéneo [1]. Lo primero que debe hacer cada individuo es comprender el enunciado de la pregunta; luego, debe revisar sus conocimientos sobre el tema, organizar la respuesta y, posteriormente, seleccionar una opción si se trata de un examen de elección múltiple o describirla si es una evaluación tipo ensayo [4]. En cada una de estas etapas influyen tanto las características propias del evaluado como también las del evaluador [5]. En el caso de este último, una serie de variables incidirán en la forma en la cual redacta un instrumento: su estilo de aprendizaje dominante, la elección de contenidos que efectúe y la relevancia asignada a cada uno, su capacidad y grado de manejo del lenguaje escrito, etc. Esta última característica condicionará la estructura semántica de la pregunta y, por tanto, las probables repuestas. No es extraño que al revisar las preguntas efectuadas por otro académico, se reconozcan errores de redacción o dificultades para entender lo que se intentó preguntar; lo mismo, y en mayor grado, ocurre con los estudiantes, quienes durante su etapa universitaria o posterior se centran en la adquisición de conocimientos y habilidades y no necesariamente en mejorar o potenciar aspectos deficientes de su comprensión lectora o escrita [1]. Por otro lado, la selección de temáticas y la valoración de contenidos también pueden sesgarse a aquello de mayor dominio del docente o a lo que, desde su perspectiva, es más relevante. En fin, los resultados de una evaluación no dependen sólo del 'objeto' que se evalúa, sino también de las peculiaridades de quienes realizan la evaluación y los vínculos que establezcan entre sí [6].

Las fuentes de subjetividad, por tanto, son múltiples y aun cuando existen mecanismos para disminuirlas y lograr instrumentos más estandarizados, como la aplicación de pruebas psicométricas [7], está claro que serán imposibles de eliminar en su totalidad.

Entonces, ¿cómo mejorar el sentido evaluativo de las pruebas estandarizadas?, ¿qué estrategia permite agregar valor educativo a estas evaluaciones?

La acumulación de evidencias y la propia experiencia con los estudiantes de pre y posgrado indican que la retroalimentación ofeedback es esencial cuando estamos frente a un acto evaluativo, independientemente de su naturaleza $[5,8]$. Dicho feedback, sin embargo, no es un proceso unidireccional desde el profesor al estudiante, sino mas bien multidireccional, ya que debe ocurrir en todas las direcciones posibles (profesor-alumno, alumno-profesor y entre pares). Por tanto, la evaluación debería ser esencialmente un acto de comunicación [6] que permitiera abrir el diálogo académico, y el mejor momento en que podría darse sería cuando todos los actores están en conocimiento de las evidencias
Departamento de Tecnología Médica. Facultad de Medicina. Universidad de Chile. Santiago, Chile.

Correspondencia: Prof. Sandra Araya Leal. Departamento de Tecnología Médica. Facultad de Medicina. Universidad de Chile. Avda. Independencia, 1027. Santiago, Chile.

E-mail: sarayaleal@gmail.com (c) 2014 FEM 
disponibles sobre un tema y pueden generar un diálogo fructífero que permita consolidar los aprendizajes y generar significado. Sobre todo, deben revisarse las preguntas con alta dispersión en las respuestas o elevados índices de error, ya que los enunciados pueden presentar errores que incidan en la interpretación del alumno o bien el sentido de la pregunta puede llegar a comprenderse de forma distinta a lo esperado. A numerosos docentes les resulta complejo, para la revisión de las evaluaciones escritas, exponer sus pautas de revisión a los estudiantes, pues sin duda se exponen a cuestionamientos y además se ven obligados a modificar la interacción docente-alumno, desde una postura de 'poder' a una que requiere mayor simetría [5], en la cual pueda establecerse el dialogo académico y los estudiantes tengan la posibilidad de exponer abiertamente sus dudas y comentarios. El docente debe adquirir en este escenario el papel de facilitador del proceso, siendo capaz de exponer las estrategias evaluativas y discutirlas con sus estudiantes; éstos, a su vez, deberán aprender a comprender la evaluación como un proceso participativo del cual son tan responsables como el docente.

En el contexto mencionado se traspasan los límites de una simple revisión de prueba; el estudiante, al hacerse parte de esta revisión, de modo necesario deberá prepararse académicamente para la discusión informada y con fundamento, desarrollando competencias discursivas que le permitan ar- gumentar y defender sus posturas, compartiendo puntos de vista con sus pares en busca del consenso y, lo más importante, entendiendo que en el mundo global, en el cual las fronteras de la información y las distancias físicas han sido derribadas, es de vital importancia comprender, argumentar y resolver, proceso que en la vida profesional será a veces en solitario, pero en numerosas ocasiones, en conjunto con un equipo de salud que requiere aprender a escuchar y compartir para luego decidir en bien del paciente.

\section{Bibliografía}

1. Bravo A, Fernández J. La evaluación convencional frente a los nuevos modelos de evaluación auténtica. Psicothema 2000; 12: 95-9.

2. Sarrias-Ramis R, Mateu L, Baillès E, Pérez J. Longitud (número de preguntas) y resultado de un examen. Educ Med 2010; 13: 187-92.

3. Torrubia R, Pérez J. La difícil objetividad de las pruebas de ensayo en la evaluación del rendimiento académico. Educ Med 2005; 8: 17-21.

4. Ayala-Valenzuela R, Messing-Grubell H. Comprender los enunciados en un examen escrito: ¿dónde está el problema? Educ Med Super 2013; 27: 211-9.

5. Blanco MA, Rodríguez T, Blanco O, Hernández L. Enfermedades de la evaluación. Educ Med Super 2013; 27: 249-58.

6. González M. La evaluación del aprendizaje: tendencias y reflexión crítica. Educ Med Super 2001; 15: 85-96.

7. Díaz P, Leyva E. Metodología para determinar la calidad de los instrumentos de evaluación. Educ Med Super 2013; 27: 269-86.

8. Fornells JM, Julià X, Arnau J, Martínez-Carretero JM. Feedback en educación médica. Educ Med 2008; 11: 7-12. 